\title{
The effects of ankle weight loading on the walking factors of adults without symptoms
}

\author{
Jea-Woong Hwang', Su-Kyoung Lee, ${ }^{2 *}$, Jin-Seong Park', Su-Hong Ahn', Kwnag-Jun Lee', Sung-Jae Lee' \\ 'Department of Biomedical Health Science, Graduate School, Dong-Eui University, Busan, Korea \\ ${ }^{2}$ Department of Physical Therapy, College of Nursing, Healthcare Sciences and Human Ecology, Dong-Eui University, Busan, Korea
}

The purpose of this study was to evaluate the components of walking adults who have no symptoms by integrating the temporal and spatial walking variables obtained from the GAITRite system. The following describes previous debates on weight-loaded walking training. The conclusion was as follows. First, there was a significant difference in walking distance between the $0 \%$ group and $1 \%$ group and between the $1 \%$ group and $2 \%$ group $(P<0.05)$. Sencond, there was a significant difference in walking velocity between the $0 \%$ group and $1 \%$ group and between the $0 \%$ group and $2 \%$ group $(P<0.05)$. Third, there was a signifi- cant difference in walking cadence between the $0 \%$ group and $1 \%$ group, between the $1 \%$ group and $2 \%$ group, and between the $0 \%$ group and $2 \%$ group $(P<0.05)$. These study results indicate that diverse amounts of weight loading can be effective for enhancing the walking factors of adults without symptoms.

Keywords: Weight-loaded, Gait rite system, Walking factors, Walking velocity and cadence

\section{INTRODUCTION}

The ability to walk freely, which means the movement of the human body from one point to another through bipedalism, is the most fundamental basis for the successful performance of an individual's daily routine (Yi, 2011). Normal walking is a functional relationship where the body's anatomical and psychological supporting systems are properly integrated and mutually depend on each other in an organic way (Kim and Yoon, 2009). Walking is a complicated motion that is possible when approximately 100 skeletal muscles coordinate with multiple joints in the upper and lower limbs (Whittlesey and Hamill, 1996). For complete walking, the following four requirements should be satisfied. First, the trunk, head, and arms above the two hip joints should be balanced. Second, support of the lower limb segments should be maintained during the stance phase. Third, the feet should be completely off the ground during the swing phase. Finally, energy that can drive the body forward needs to be supplied (Olney and Richard, 1996).
There are two ways of expressing walking: gait and walk. Gait refers to the controlling mechanism of walking and walk refers to the appearance of walking in general (Levine et al., 2012). Everyone performs bipedal walk, but each person has a different gait.

Walking is an exercise that requires low-intensity endurance. It helps improve physical strength and the circulation function of women and middle-aged or older people (American College of Sports Medicine, 2000). It is also effective in weight loss and the improvement of the cardiopulmonary function (Shono et al., 2001). Walking is an effective exercise that has a relatively low risk of injury to the musculoskeletal system due to its small effect on the human body (Park et al., 2007). However, as it requires a long time due to its low energy consumption, walking as an exercise has the disadvantage of being boring (Kim et al., 2002).

To counteract the shortcoming of this exercise that requires a long time, ways to increase exercise consumption during the same amount of time have been introduced that can save time and increase the intensity and efficiency of the exercise (Auble and
*Corresponding author: Su-Kyoung Lee (iD https://orcid.org/0000-0002-4916-2188 Department of Physical Therapy, College of Nursing, Healthcare Sciences and Human Ecology, Dong-Eui University, 176 Eomgwang-ro, Busanjin-gu, Busan 47340 , Korea

Tel: +82-51-890-4223, Fax: +82-505-182-6881, E-mail: ptlsk@deu.ac.kr

Received: March 12, 2017 / Accepted: July 17, 2017
This is an Open Access article distributed under the terms of the Creative Commons Attribution Non-Commercial License (http://creativecommons.org/licenses/by-nc/4.0/) which permits unrestricted non-commercial use, distribution, and reproduction in any medium, provided the original work is properly cited. 
Schwartz, 1991). Examples include walking while holding a dumbbell in each hand or wearing a sandbag around each ankle (Yang, 1996). In particular, a lot of people do weight-loaded exercise using sandbags because sandbags are inexpensive and easy to wear. Walking exercise with added weight loading is reported to be more effective than normal walking exercise (Burse et al., 1979; Pandolf and Goldman, 1975).

There have been a variety of studies regarding weight loading on the lower limbs. A study reported that exercise effects increase when the attachment location of the weight load is nearer to the lower limb than the upper limb and that the minimum weight loading is $2 \%$ of body weight, with $1 \%$ on each lower limb (Yang, 1996). A study that compared the activity of the gluteus medius muscle during walking by applying a weight load of $0 \%, 1 \%$, and $2 \%$ of body weight reported significant activation in the case of $1 \%$ loading (Lee, 2013).

Studies have been published that argue that weight-loaded training is effective for walking and the activation of the muscle strength of the lower limb. However, few studies have used weight load to compare the walking factors of adults who do not have symptoms. Hence, this study examined the impact of training with weight loading, which many people use in daily life, on walking according to different weight loads by using temporal and spatial walking analyses.

\section{MATERIALS AND METHODS}

\section{Participants}

Male and female adults living in Busan, Korea were selected as the research subjects for this study. All of the participants had not experienced any injury in the lower limbs over the past 6 months and were familiar with walking as they were already walking for more than 2 hr every day. Before the experiment, the purpose and method of this experiment was explained to them sufficiently. All of the subjects participated voluntarily. After submitting consent, they participated in the experiment in random order.

\section{Measurement tool}

This study used GAITRite (CIR system Inc., Franklin, New Jersey, USA) to measure the temporal and spatial variables of walking. GAITRite is an electronic walking plate that has a walking area of $61-\mathrm{cm}$ width and $366-\mathrm{cm}$ length. As a subject walks on the walking lane, a pressure detection device attached to the plate captures the subject's walking. The walking analyzer generates and stores records in computer files so that users can collect information regarding the temporal and spatial walking variables.

\section{Measurement method}

The entire process of the study's experiment was sufficiently explained to all the subjects. The experiment was implemented after resting so that the subjects were familiar with the environment. For accuracy, the measurement was conducted by a single tester.

For the walking measurement, a tester showed an example and let the subjects walk at their comfortable walking velocity and maintain the velocity to the end. Walking began $2 \mathrm{~m}$ in front of the walking plate upon a verbal signal from the tester. Then, the subjects walked over to the walking plate and returned after walking $2 \mathrm{~m}$ more in distance.

This process was repeated 3 times and walking velocity, step length, cadence, stride, and stride length were measured. The average of the three measurements was used for the analysis.

\section{Weight-loading method}

Before the measurement, weight that corresponded to $0 \%, 1 \%$, and $2 \%$ of the individual's body weight was attached at $5 \mathrm{~cm}$ above the left and right ankle bones using sandbags with Velcro-type straps.

\section{Data analysis}

This study used IBM SPSS ver. 18.0 (IBM Co., Armonk, NY, USA) for the analysis of the collected data. We used a repeated measures analysis of variance for the comparison analysis of the temporal and spatial variables, the kinematic variable, and the kinetic variable of each group. The significance level was set at $\alpha=0.05$.

\section{RESULTS}

\section{General characteristics of the research subjects}

The research subjects included 11 men and 16 women whose average age was $22.19 \pm 1.96$ years old, average height was $166.33 \pm 9.22 \mathrm{~cm}$, and average body weight was $61.52 \pm 11.44 \mathrm{~kg}$ (Table 1).

Table 1. General characteristics of the subjects $(n=27)$

\begin{tabular}{lc}
\hline Characteristic & Value \\
\hline Gender (male:female) & $11: 16$ \\
Age $(\mathrm{yr})$ & $22.19 \pm 1.96$ \\
Height $(\mathrm{cm})$ & $166.33 \pm 9.22$ \\
Weight $(\mathrm{kg})$ & $61.52 \pm 11.44$ \\
\hline
\end{tabular}

Values are presented as number or mean \pm standard deviation. 
Table 2. Within-subject contrast test of walking distance

\begin{tabular}{lccccc}
\hline Walking distance & Type III SS & Degree of freedom & Mean square & $F$ & Significance probability \\
\hline Levels 1 and 2 & $7,733.794$ & 1 & $7,733.794$ & 1.756 & 0.197 \\
Levels 2 and 3 & $20,106.453$ & 1 & $20,106.453$ & 4.838 & $0.037^{*}$ \\
Levels 1 and 3 & $2,900.386$ & 1 & $2,900.386$ & 0.570 & 0.457 \\
\hline
\end{tabular}

${ }^{*} P<0.05$.

Table 3. Within-subject contrast test of walking velocity

\begin{tabular}{lccccc}
\hline Walking velocity & Type III SS & Degree of freedom & Mean square & $F$ & Significance probability \\
\hline Levels 1 and 2 & 272.653 & 1 & 272.653 & 6.181 & $0.020^{*}$ \\
Levels 2 and 3 & 42.563 & 1 & 42.563 & 1.234 & 0.277 \\
Levels 1 and 3 & 530.670 & 1 & 530.670 & 8.381 & $0.008^{* *}$ \\
\hline
\end{tabular}

${ }^{*} P<0.05$. ${ }^{* *} P<0.01$.

Table 4. Within-subject contrast test of walking cadence

\begin{tabular}{lccccc}
\hline Walking cadence & Type III SS & Degree of freedom & Mean square & $F$ & Significance probability \\
\hline Levels 1 and 2 & 209.446 & 1 & 209.446 & 16.609 & $0.000^{* *}$ \\
Levels 2 and 3 & 46.413 & 1 & 46.413 & 5.057 & $0.033^{*}$ \\
Levels 1 and 3 & 453.050 & 1 & 453.050 & 24.593 & $0.000^{* *}$ \\
\hline
\end{tabular}

${ }^{*} P<0.05$. ${ }^{* *} P<0.01$.

Table 5. Within-subject contrast test of walking step length

\begin{tabular}{lccccc}
\hline Walking step length & Type III SS & Degree of freedom & Mean square & $F$ & Significance probability \\
\hline Levels 1 and 2 & 0.699 & 1 & 0.699 & 0.107 & 0.746 \\
Levels 2 and 3 & 0.406 & 1 & 0.406 & 0.098 & 0.757 \\
Levels 1 and 3 & 0.040 & 1 & 0.040 & 0.004 & 0.947 \\
\hline
\end{tabular}

\section{Change in and comparison of the temporal and spatial} walking variables

\section{Walking distance}

In the measurement of walking distance, the group with $0 \%$ added weight had $813.80 \pm 48.00 \mathrm{~cm}, 1 \%$ had $830.73 \pm 50.64$ $\mathrm{cm}$, and $2 \%$ had $803.44 \pm 49.19 \mathrm{~cm}$. There was a significant difference between the $1 \%$ group and $2 \%$ group $(P<0.05)$ (Table 2$)$.

\section{Walking velocity}

In the measurement of walking velocity, the $0 \%$ group had $129.81 \pm 14.83 \mathrm{~cm} / \mathrm{sec}, 1 \%$ had $126.63 \pm 16.92 \mathrm{~cm} / \mathrm{sec}$, and $2 \%$ had $125.38 \pm 17.18 \mathrm{~cm} / \mathrm{sec}$. There was a significant difference between the $0 \%$ group and $1 \%$ group and between the $0 \%$ group and $2 \%$ group $(P<0.05)$ (Table 3$)$.

\section{Cadence}

In the measurement of walking cadence, the $0 \%$ group had $117.88 \pm 8.71 \mathrm{step} / \mathrm{min}, 1 \%$ had $115.10 \pm 9.39 \mathrm{step} / \mathrm{min}$, and $2 \%$ had $113.79 \pm 9.43 \mathrm{step} / \mathrm{min}$. A significant difference was observed between the $0 \%$ group and $1 \%$ group, between the $0 \%$ group and $2 \%$ group, and between the $1 \%$ group and $2 \%$ group $(P<$ 0.05) (Table 4).

\section{Step length}

In the measurement of step length, the $0 \%$ group had $66.05 \pm$ $5.31 \mathrm{~cm}, 1 \%$ had $65.89 \pm 5.44 \mathrm{~cm}$, and $2 \%$ had $66.01 \pm 6.06 \mathrm{~cm}$. There was no statistically significant difference in the bwtweengroup comparison (Table 5).

\section{Stride length}

In the measurement of stride length, the $0 \%$ group had $132.30 \pm$ $10.65 \mathrm{~cm}, 1 \%$ had $131.80 \pm 10.90 \mathrm{~cm}$, and $2 \%$ had $132.12 \pm$ $12.00 \mathrm{~cm}$. There was no statistically significant difference in the between-group comparison (Table 6).

\section{Double support time}

In the measurement of the double support time of walking, the $0 \%$ group had $0.21 \pm 0.04 \mathrm{sec}, 1 \%$ had $0.21 \pm 0.04 \mathrm{sec}$, and $2 \%$ 
Table 6. Within-subject contrast test of walking stride length

\begin{tabular}{lccccc}
\hline Walking stride length & Type III SS & Degree of freedom & Mean square & $F$ & Significance probability \\
\hline Levels 1 and 2 & 6.589 & 1 & 6.589 & 0.223 & 0.641 \\
Levels 2 and 3 & 2.772 & 1 & 2.772 & 0.155 & 0.697 \\
Levels 1 and 3 & 0.813 & 1 & 0.813 & 0.022 & 0.883 \\
\hline
\end{tabular}

Table 7. Within-subject contrast test of double support time while walking

\begin{tabular}{lccccc}
\hline Double support time while walking & Type III SS & Degree of freedom & Mean square & $F$ & Significance probability \\
\hline Levels 1 and 2 & 0.000 & 1 & 0.000 & 0.462 & 0.503 \\
Levels 2 and 3 & 0.000 & 1 & 0.000 & 0.022 & 0.882 \\
Levels 1 and 3 & 0.000 & 1 & 0.000 & 0.322 & 0.575 \\
\hline
\end{tabular}

had $0.21 \pm 0.05 \mathrm{sec}$. There was no statistically significant betweengroup difference (Table 7).

\section{DISCUSSION}

This study examined the temporal and spatial changes in adults without symptoms due to weight by using walking analysis. Studies related to walking began with the most fundamental descriptive research on the walking phase and have evolved to incorporate more complicated and diverse methods and measurement tools. The related literature is now building a unique domain, for example, a recent study used a mathematical modeling technique. Clinical studies focusing on the medical diagnosis and improvement of motions that can cause surgical impediments in patients with walking impairment are under active progress (Harris and Wertsch, 1994).

Our study evaluated the components of walking adults who have no symptoms by integrating the temporal and spatial walking variables obtained from the GAITRite system. The following describes previous debates on weight-loaded walking training.

Yang (1996) reported that exercise effects, such as energy metabolism or rate of perceived exertion, increased as the location of weight loading goes farther from the trunk or upper limb toward the ankle. A study that examined the activation of the lower limb in the stance phase during walking using diverse weight amounts $(0 \mathrm{~kg}, 0.5 \mathrm{~kg}$, and $1 \mathrm{~kg})$ reported a significant difference in the case of $0.5 \mathrm{~kg}$ vertical loading (Lee et al., 2013). Lee (2013) studied weight loading that corresponded to $0 \%, 1 \%$, and $2 \%$ of body weight on the lower limbs in the swing phase side of 40 young men in their 20s and 30s and compared the activity of the gluteus medius muscle in the stance phase side. The study reported a significant activation of the gluteus medius muscle in the case of $1 \%$ loading. The study also conducted a comparison analysis among the $0 \%, 1 \%$, and $2 \%$ groups and reported a significant difference between $1 \%$ and $2 \%$, showing similar results to previous studies. Lee and Lee (2011) provided 6-week treadmill walking training to subjects consisting of patients with stroke by dividing them into a weight-loading group on the unaffected side where $5 \%$ of body weight was applied, a weight-loading group on the affected side with the same amount of weight loading, and a nonweight-loading group. In the study results, the group that had weight loading on the unaffected side showed a significant difference in temporal and spatial walking factors. It is conjectured that our study could have produced significant results in the walking factor if we had applied $1 \%$ weight loading to patients.

In the analysis results of this study, a significant difference in walking distance was observed between the $1 \%$ group and $2 \%$ group when walking distance was high in the $1 \%$ group and low in the $2 \%$ group. There was a significant difference in walking velocity between the $0 \%$ group and $1 \%$ group and between the $1 \%$ group and $2 \%$ group when walking velocity decreased as weight increased. Cadence also showed a significant difference in all of the between-group comparisons when cadence decreased according to weight increase. Lee (2013) reported that $1 \%$ weight loading increases the activity of the gluteus medius muscle during walking, but $2 \%$ weight loading decreases its activity. It is conjectured that $1 \%$ weight loading caused an increase in walking distance by providing stability to the lower limb in the stance phase side due to the increased activity of the gluteus medius muscle, while $2 \%$ weight loading decreased distance because it acted as an interfering factor by reducing the activity of the gluteus medius muscle during walking. Walking velocity and cadence are proportional to each other (Lin et al., 2006) and cadence decreases more in an overweight group than in a low body weight group (Kang and Park, 2014). This study also confirmed the consistency of walking velocity and cadence. A decrease in walking 
velocity and cadence due to an increase of weight load can be attributed to limited joint mobility because of the weight loading.

Considering the results of the previous literature and this study, weight loading that corresponds to $1 \%$ of body weight improves walking ability, which is expected to contribute to independent walking and better daily life. We believe that diverse studies are needed that can be applied to a broader range of patients in the future.

This study examined the temporal and spatial changes in the walking factors of male and female adults without symptoms due to weight loading. We selected 20 male and female adults that had no symptoms and investigated the temporal and spatial walking variables of their walking factors using the GAITRite system. Below is a summary of the study results.

(a) There was a significant difference in walking distance between the $0 \%$ group and $1 \%$ group and between the $1 \%$ group and $2 \%$ group $(P<0.05)$.

(b) There was a significant difference in walking velocity between the $0 \%$ group and $1 \%$ group and between the $0 \%$ group and $2 \%$ group $(P<0.05)$.

(c) There was a significant difference in walking cadence between the $0 \%$ group and $1 \%$ group, between the $1 \%$ group and $2 \%$ group, and between the $0 \%$ group and $2 \%$ group $(P<0.05)$.

These study results indicate that diverse amounts of weight loading can be effective for enhancing the walking factors of adults without symptoms.

\section{CONFLICT OF INTEREST}

No potential conflict of interest relevant to this article was reported.

\section{REFERENCES}

American College of Sports Medicine. ACSM's guidelines for exercise testing and prescription. 6th ed. Philadelphia (PA): Lippincott Williams and Wilkins; 2000.

Auble TE, Schwartz L. Physiological effects of exercising with handweights. Sports Med 1991;11:244-256.

Burse RL, Pandolf KB, Goldman RF. Physical conditioning of sedentary young men with ankle weights during working hours. Ergonomics
1979;22:69-78

Harris GF, Wertsch JJ. Procedures for gait analysis. Arch Phys Med Rehabil 1994;75:216-225.

Kang SW, Park YS. Aging: difference of postural stability and gait by BMI level in the elderly. J Phys Growth Motor Dev 2014;22:61-66.

Kim G, Yoon NM. A study on kinetic gait analysis of the normal adult. J Korean Soc Phys Ther 2009;21:87-95.

Kim YK, Kwon YK, Jang YW. Physical response in treadmill walking exercise after artificial weight loading. Korean J Sport Med 2002;20:72-81.

Lee SK. The effect of a vertical load on gluteus medius activity and gait characteristics during walking. J Phys Ther Sci 2013;25:1397-1399.

Lee SK, Jung JM, Lee SY. Gluteus medius muscle activation on stance phase according to various vertical load. J Back Musculoskelet Rehabil 2013;26:159-161.

Lee SW, Lee HS. The effect of treadmill-based leg weight loading training on balance and gait in stroke patients. J Spec Educ Rehabil Sci 2011; 50:89-111.

Levine D, Jim R, Whittle M. Whittle's gait analysis. 5th ed. New York: Churchill Livingstone; 2012.

Lin PY, Yang YR, Cheng SJ, Wang RY. The relation between ankle impairments and gait velocity and symmetry in people with stroke. Arch Phys Med Rehabil 2006;87:562-568.

Olney SJ, Richard C. Hemiparetic gait following stroke. Part I: characteristic. Gait Posture 1996;4:136-148.

Pandolf KB, Goldman RF. Physical conditioning of less fit adults by use of leg weight loading. Arch Phys Med Rehabil 1975;56:255-261.

Park SH, Han TK, Lee SH, Kang YC, Kang HS. Effects of two different intensities of a 12 week-walking program on body composition, abdominal fat, and cardiorespiratory fitness in obese women. Exerc Sci 2007; 16:1-10.

Shono T, Fujishima K, Hotta N, Ogaki T, Masumoto K. Cardiorespiratory response to low-intensity walking in water and on land in elderly women. J Physiol Anthropol Appl Human Sci 2001;20:269-274.

Whittlesey SN, Hamill J. An alternative model of the lower extremity during locomotiom. J Appl Biomech 1996;12:269-279.

Yang JS. Physiological responses to walking exercise with added weight at different locations in normal subjects. Korean J Phys Educ 1996;35: 130-143.

Yi JH. Kinetic analysis of the lower limb in visual handicap children. J Korea Acad Ind Cooper Soc 2011;12:3952-3958. 